\title{
Conference Paper Physical Investigations on ZnO:Ni Layers Deposited by Spray Pyrolysis
}

\author{
M. Rajendraprasad Reddy, ${ }^{1}$ V. Supriya, ${ }^{1}$ M. Sugiyama, ${ }^{2}$ and K. T. $\operatorname{Ramakrishna} \operatorname{Reddy}{ }^{1}$ \\ ${ }^{1}$ Thin Film Laboratory, Department of Physics, Sri Venkateswara University, Tirupati 517 502, India \\ ${ }^{2}$ School of Electrical Engineering, Tokyo University of Sciences, Noda-278-8510, Chiba, Japan
}

Correspondence should be addressed to K. T. Ramakrishna Reddy; ktrkreddy@gmail.com

Received 4 January 2013; Accepted 26 May 2013

Academic Editors: P. Agarwal and B. Bhattacharya

This Conference Paper is based on a presentation given by M. Rajendraprasad Reddy at "International Conference on Solar Energy Photovoltaics" held from 19 December 2012 to 21 December 2012 in Bhubaneswar, India.

Copyright (C) 2013 M. Rajendraprasad Reddy et al. This is an open access article distributed under the Creative Commons Attribution License, which permits unrestricted use, distribution, and reproduction in any medium, provided the original work is properly cited.

\begin{abstract}
Nickel-doped $\mathrm{ZnO}$ (ZnO:Ni) layers have been deposited on glass substrates by a spray pyrolysis method using zinc acetate and nickel sulphate as precursors. The layers were grown at different substrate temperatures, $T_{s}$, that vary in the range $250-350^{\circ} \mathrm{C}$. During deposition, the precursor concentration and Ni-doping content were maintained constant at $0.1 \mathrm{M}$ and $10 \%$, respectively. The X-ray diffraction (XRD) analysis showed that all the layers were polycrystalline in nature with the (002) plane as the preferred orientation and exhibited hexagonal wurtzite structure. A sharp increment in the intensity of predominant peak with the substrate temperature was observed consistently that indicated an improvement in the crystallinity of the layers. The Raman studies confirmed the hexagonal wurtzite crystal structure of $\mathrm{ZnO}$ and indicated defect states. The X-ray photoelectron spectroscopy (XPS) studies revealed the characteristic peaks of the elements involved in the films and their ionic states. The optical transmittance of the films was higher than $80 \%$ and the evaluated energy band gap decreased from $3.17 \mathrm{eV}$ to $3.13 \mathrm{eV}$ with the increase of substrate temperature.
\end{abstract}

\section{Introduction}

Zinc oxide $(\mathrm{ZnO})$ is an important semiconductor for several applications and forms a building block in the fabrication of many advanced device technologies [1-3]. This is mainly because of its wide band gap $(3.37 \mathrm{eV})$, large excitonic binding energy $(\sim 60 \mathrm{meV})$, high optical transmittance $(>80 \%)$, chemical stability, hardness, and good piezoelectric properties [4]. Attempts have been made to improve the properties of $\mathrm{ZnO}$, particularly the electrical behavior, by doping with different metal ions using different techniques to achieve the multifunctional behaviour. The theoretical prediction of ferromagnetism in $\mathrm{Ni}$-doped $\mathrm{ZnO}$ triggered the interest of scientific community due to its numerous applications in the field of spintronics and magneto-optical devices. The resulting material is known as dilute magnetic semiconductor (DMS) in which the d-orbital electrons of transition metal ions interact with the s- and p-orbit electrons of the host matrix [5]. Secondly, ZnO layers with minor Ni-doping could be also used for solar cell application in addition to DMS provided they exhibit high transmittance, wide band gap, and low electrical resistivity, although at high Ni-doping concentrations the optical transmittance of $\mathrm{ZnO}$ layers decreases. $\mathrm{ZnO}$ thin films, doped with different transition metal ions, were prepared by various techniques and their properties investigated. Spray pyrolysis is a simple and low cost wet chemical method that has been used to deposit metal oxide semiconductors [6]. Further, it allows the coating of layers over large areas and therefore it is easy to integrate the process in an industrial production line. In the present work, spray pyrolysis was used to deposit $\mathrm{Ni}$-doped $\mathrm{ZnO}$ films on glass substrates and the physical behavior of the layers has been investigated and reported. 


\section{Experimental Details}

$\mathrm{Ni}$-doped $\mathrm{ZnO}$ thin films were prepared on glass substrates by spray pyrolysis technique. The spray solution was the combination of equimolar $(0.1 \mathrm{M})$ solutions of zinc acetate and nickel sulphate in presence of distilled water. The substrate temperature was varied from $250^{\circ} \mathrm{C}$ to $350^{\circ} \mathrm{C}$. Compressed air was used as the carrier gas. The carrier gas and solution were fed into the spray nozzle at a predetermined constant flow rates, $6 \mathrm{~L} / \mathrm{min}$ and $8 \mathrm{~mL} / \mathrm{min}$, respectively. The nozzle to substrate distance was fixed at $25 \mathrm{~cm}$. In order to have a uniform coating on substrate, the spray head is connected to a stepper motor system that moves in $x-y$ direction periodically.

The structural properties such as the preferred orientation, crystal structure, and average crystallite size were determined by using Siefert X-ray diffractometer with $\mathrm{CuK} \alpha$ $(\lambda=1.542 \AA)$ radiation source. The films were scanned within the $2 \theta$ range, $20^{\circ}-70^{\circ}$ at a scan rate of $1^{\circ} / \mathrm{min}$. The identification of different phases present in the films was done using the Renishaw Ramanscope 2000 micro spectrometer in the wavenumber range $200-1200 \mathrm{~cm}^{-1}$. It involves the measurement of Raman intensity as a function of wavenumber of the inelastic light scattering that results from the excitation of vibrations in crystalline films [7]. The valence states of elements present in the films were analysed by Xray photoelectron spectroscopy (XPS) studies. The XPS peaks were calibrated against the $\mathrm{Cls}$ peak of carbon present at $284.6 \mathrm{eV}$ [8]. In the present study, the elemental composition of the layers was studied using VG MICROTECH ESCA2000 XPS system generating non-monochromatic Xrays. The optical properties of the experimental films such as the optical transmittance, reflectance, and energy band gap were evaluated using Perkin-Elmer Lambda 950 UV-Vis-NIR double beam spectrophotometer in the wavelength range of $300-2400 \mathrm{~nm}$.

\section{Results and Discussions}

The visual appearance of the as-grown films indicated that the layers were pale green in appearance, uniform, and pin hole free. The scratch tape test revealed that the layers were strongly adherent to the substrate surface.

3.1. X-Ray Diffraction Studies. The X-ray diffraction patterns of $\mathrm{Ni}$-doped $\mathrm{ZnO}$ thin films deposited at various substrate temperatures are depicted in Figure 1. The spectra showed multiple peaks, indicating that all the as-grown layers were polycrystalline in nature. The spectra also indicated (002) plane as the dominant orientation among the different peaks that had the highest intensity. The evaluated crystal structure was found to be hexagonal wurtzite structure. The other peaks observed correspond to the (100), (101), (102), (110), (103), and (112) planes of $\mathrm{ZnO}$ structure. The doping of $\mathrm{ZnO}$ films with $\mathrm{Ni}^{+2}$ ions does not have appreciable effect on the crystal structure of the films. Further, the X-ray diffraction pattern showed an increase of intensity of all the diffraction

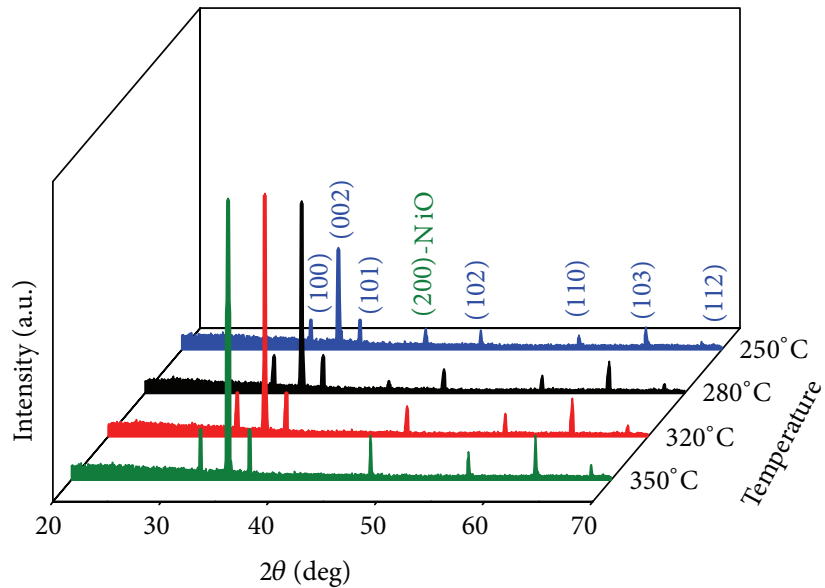

FIgure 1: XRD pattern of $\mathrm{ZnO}: \mathrm{Ni}$ films deposited at different substrate temperatures.

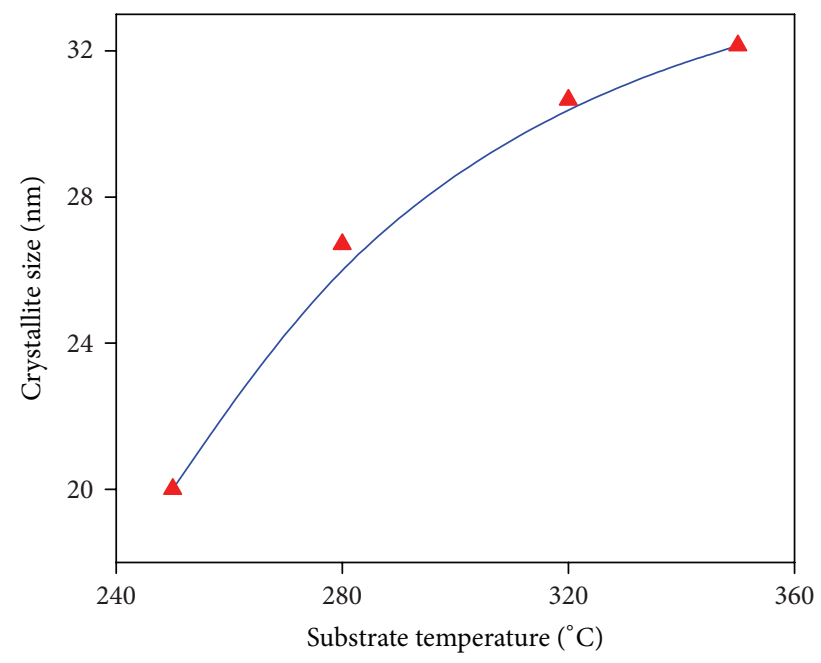

FIGURE 2: Variation of crystallite size with substrate temperature.

peaks with the increase of substrate temperature, indicating an improvement in the crystallinity of the layers.

The average crystallite size $d_{h k l}$ was estimated according to the following Debye-Scherrer's equation [9]:

$$
d_{h k l}=\frac{k \lambda}{\beta \cos (2 \theta)},
$$

where $\lambda$ is the wavelength of X-rays used, $\theta$ is the Bragg's angle of diffraction, $\beta$ is the full width at half maximum intensity of the main peak observed at $2 \theta=34.74^{\circ}$ in radian, and $k$ is a constant, chosen as $\sim 0.9$. The variation of crystallite size with substrate temperature is shown in Figure 2. The average crystallite size of the films increased with the substrate temperature. These results are in good agreement with the data reported by Kaneva and Dushkin on Ni-doped $\mathrm{ZnO}$ films formed by sol-gel dip coating [10].

3.2. Raman Measurements. Raman scattering, which is very sensitive to the microstructure of thin films, was carried out 


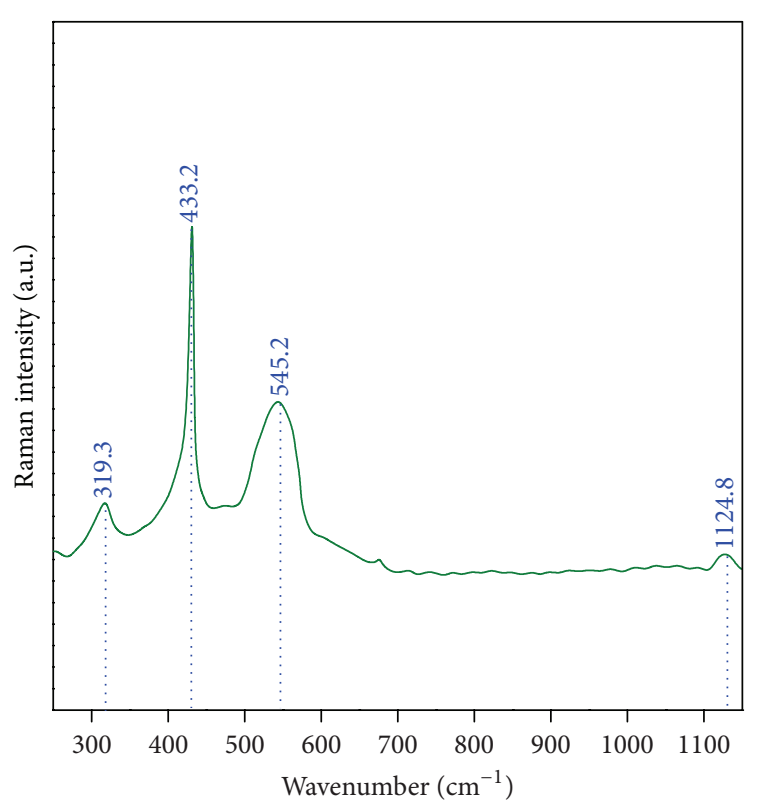

FIgUre 3: Raman spectrum of the $\mathrm{ZnO}$ :Ni films deposited at $350^{\circ} \mathrm{C}$.

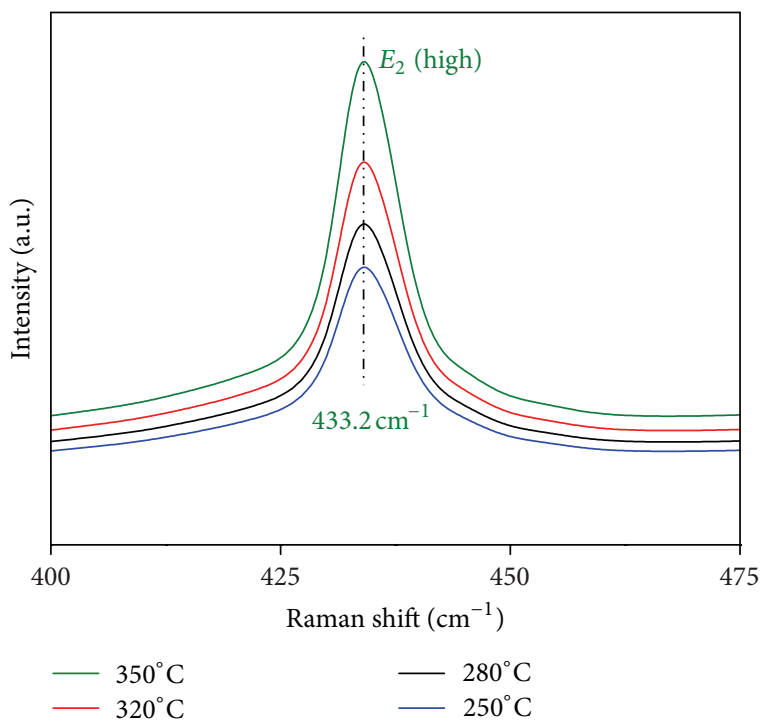

FIgURE 4: Wide scan Raman active phonon mode intensity for $\mathrm{ZnO}: \mathrm{Ni}$ films.

for the deposited films in order to investigate the influence of substrate temperature on the crystal structure and to detect the presence of any secondary phases related to nickel. Figure 3 shows the Raman spectra of a typical $\mathrm{ZnO}: \mathrm{Ni}$ film formed at $350^{\circ} \mathrm{C}$ that indicates various Raman active phonon modes at different wave numbers in the range 250$1150 \mathrm{~cm}^{-1}$. The observed phonon modes are related to the structure of $\mathrm{ZnO}$ with the space group of $\mathrm{C}_{6}^{4}$ with two familiar units per primitive cell with all atoms occupying $\mathrm{C}_{3 \mathrm{~V}}$ sites [11]. The intensity of main peak, present at $433.2 \mathrm{~cm}^{-1}$ in the spectrum, has been increased with the increase of substrate temperature and is shown in Figure 4. This infers

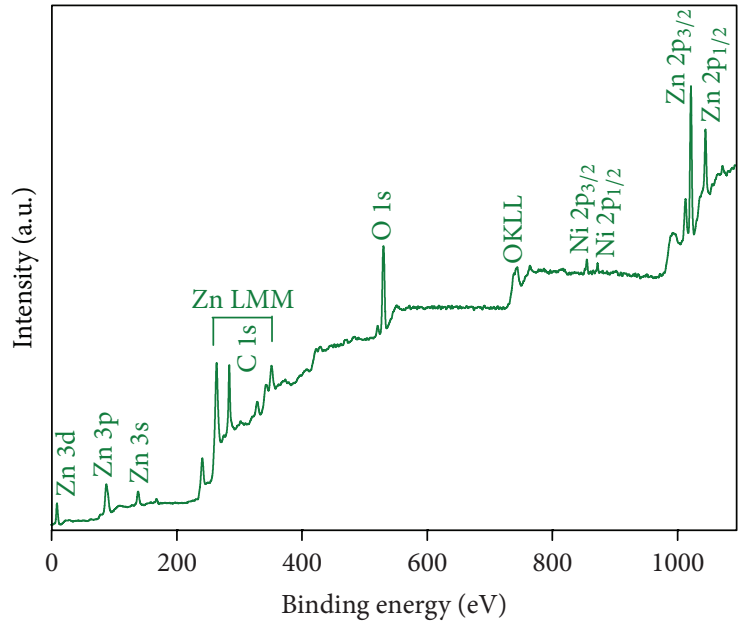

FIGURE 5: XPS spectrum of $\mathrm{ZnO}$ :Ni film grown at substrate temperature $350^{\circ} \mathrm{C}$.

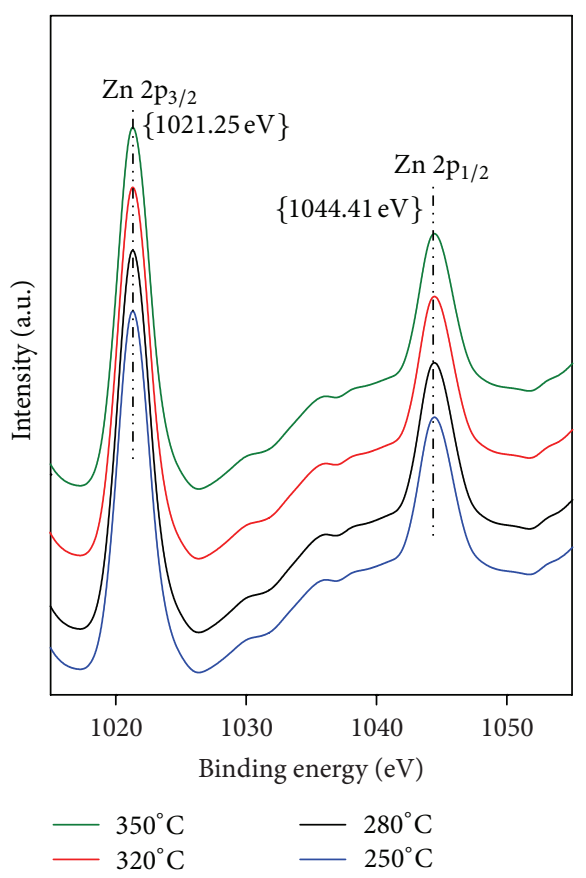

Figure 6: XPS spectra of $\mathrm{Zn}$ in $\mathrm{ZnO}$ :Ni films.

that the crystallinity of the layers is increasing with the rise of deposition temperature. No other secondary phases were observed in the Raman spectra. This suggested that Ni atoms have successfully incorporated into $\mathrm{Zn}$ lattice sites.

3.3. XPS Studies. The composition and chemical state of the elements present in $\mathrm{Ni}$-doped $\mathrm{ZnO}$ thin films deposited at different substrate temperatures were studied using XPS measurements. Figure 5 shows the wide scan XPS spectra of $\mathrm{ZnO}: \mathrm{Ni}$ film deposited at substrate temperature $350^{\circ} \mathrm{C}$. The spectra showed all the peaks related to $\mathrm{Zn}, \mathrm{O}$ and $\mathrm{Ni}$ elements present in the layers in addition to C. Figures 6, 7 , and 8 show the $\mathrm{Zn} 2 \mathrm{p}_{3 / 2}$ and $\mathrm{Zn} 2 \mathrm{p}_{1 / 2}$, O1s, Ni $2 \mathrm{p}_{3 / 2}$, 


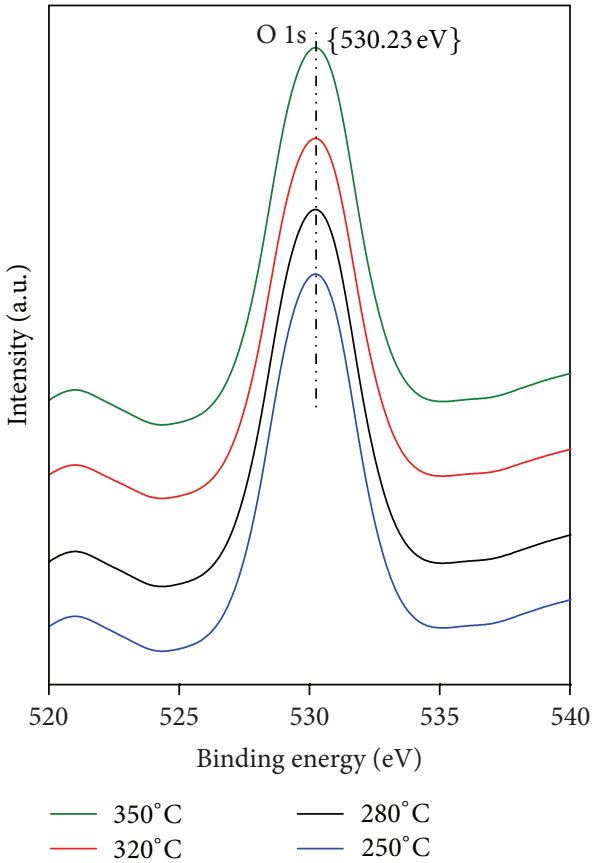

Figure 7: XPS spectra of O in ZnO:Ni films.

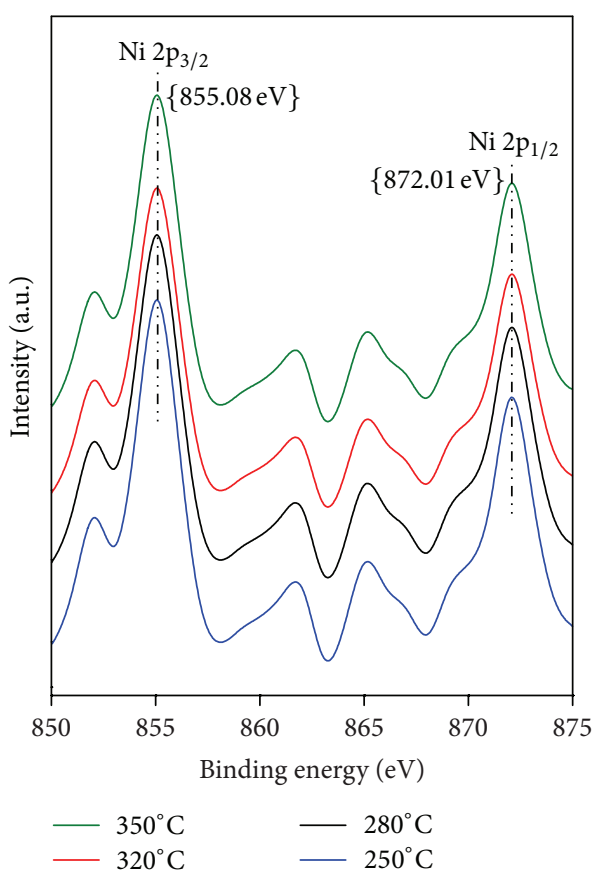

FIGURE 8: XPS spectra of $\mathrm{Ni}$ in $\mathrm{ZnO}: \mathrm{Ni}$ films.

Ni $2 p_{1 / 2}$ peaks respectively present in the layers deposited at various substrate temperatures. The presence of the peaks related to both $\mathrm{Zn}$ and $\mathrm{O}$ at appropriate binding energies is in agreement with the reported values, which indicates +2 state of $\mathrm{Zn}$ in the films. Further, the Ni $2 \mathrm{p}_{3 / 2}$ peak is observed at a binding energy of $\sim 854.15 \mathrm{eV}$, which is different from the binding energy value of metallic $\mathrm{Ni}(852.7 \mathrm{eV})$ or $\mathrm{Ni}^{+2}$ in $\mathrm{NiO}$

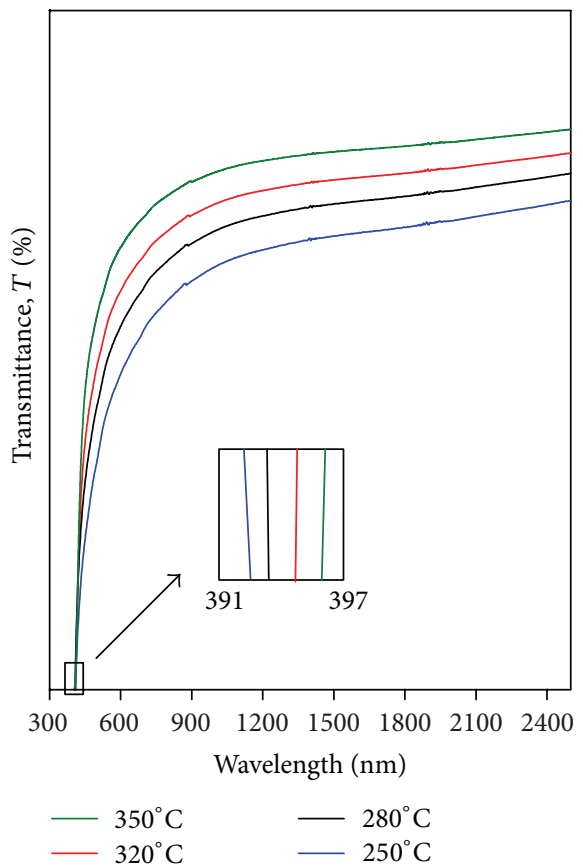

Figure 9: UV-Vis-NIR transmission curves of $\mathrm{ZnO}$ :Ni films.

$(853.5 \mathrm{eV})$ or $\mathrm{Ni}^{+3}$ in $\mathrm{Ni}_{2} \mathrm{O}_{3}(857.3 \mathrm{eV})$ [12]. This infers that nickel of Ni-doped $\mathrm{ZnO}$ thin films is in +2 valence state. Therefore, it is likely that there is a replacement of $\mathrm{Zn}^{+2}$ by $\mathrm{Ni}^{+2}$ in the $\mathrm{ZnO}$ lattice. The increase of intensity of peaks with substrate temperature attributes good crystallinity to the grown films.

3.4. Optical Studies. The optical transmittance versus wavelength spectra of the films grown at various substrate temperatures is presented in Figure 9. All the spectra revealed an optical transmittance $>65 \%$ in the films and the transmittance increases with the increase of substrate temperature. Also the spectra showed a steep fall in transmittance, indicating the presence of a direct optical transition in the films. Further, there was a slight red shift in the transmittance spectra with the increase of substrate temperature, which can be seen from the inset of Figure 9. The observed red shift is in accordance with the results reported by Chauhan on nickel doped $\mathrm{ZnO}$ nanoparticles synthesized by coprecipitation method [13].

The energy band gap of the films was determined by using the relationship

$$
\alpha=A\left(h v-E_{g}\right)^{n},
$$

where $h v$ is the photon energy, $\alpha$ is the absorption coefficient, $E_{g}$ is the optical energy band gap, and $A$ is a constant. The exponent " $n$ " depends on the type of optical transition involved and it may have values $1 / 2,2,3 / 2$, and 3 corresponding to the allowed direct, allowed indirect, forbidden direct, and forbidden indirect transmissions, respectively [14]. In the present investigation, the data followed the relation for $n=1 / 2$ and the value of band gap was determined by extrapolating the straight line portion of $(\alpha h v)^{2}$ versus 


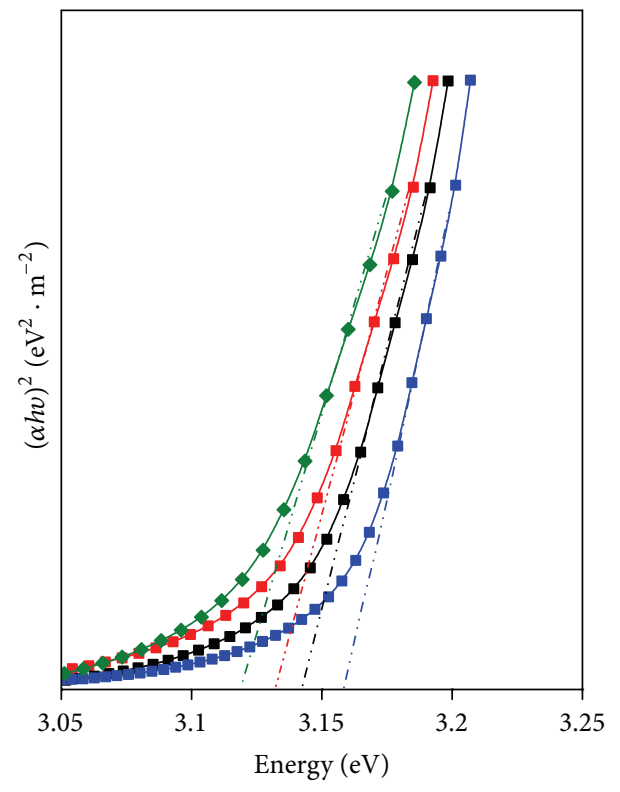

Figure 10: Plot of $(\alpha h v)^{2}$ versus photon energy $(h v)$ for $\mathrm{ZnO}: \mathrm{Ni}$ films.

$h v$ plot onto $h v$ axis [15]. Figure 10 shows the variation of $(\alpha h v)^{2}$ with $h v$ for the experimental films. The values of energy band gap obtained for the films grown at different substrate temperatures decreased from $3.17 \mathrm{eV}$ to $3.13 \mathrm{eV}$ with the increase of temperature. This indicated a shift in the band edge towards lower energy side. This small variation in band gap is attributed to the Moss-Burstein effect generally observed in polycrystalline thin films $[16,17]$.

\section{Conclusions}

The Ni-doped $\mathrm{ZnO}$ thin films were formed on glass substrates by spray pyrolysis method. The films were formed at different substrate temperatures that vary from $250^{\circ} \mathrm{C}$ to $350^{\circ} \mathrm{C}$. The $\mathrm{XRD}$ results indicated a strong (002) preferred orientation with wurtzite crystal structure. The evaluated crystallite size varied in the range $20-31 \mathrm{~nm}$. The Raman spectra showed an active phonon mode at $433.2 \mathrm{~cm}^{-1}$ corresponding to $\mathrm{ZnO}$, without any secondary phases related to Ni. The XPS measurements confirmed the presence of $\mathrm{Ni}$ in the +2 state. The films had an optical transmittance $>65 \%$ and the energy band gap decreased with the increase of substrate temperature from $3.17 \mathrm{eV}$ to $3.13 \mathrm{eV}$ due to Moss-Burstein shift.

\section{Acknowledgments}

The authors would like to thank Mr. Y. Murata and Mr. Y. Shimamoto of the Department of Electrical Engineering, Tokyo University of Sciences (Noda Campus), for the XPS measurements.

\section{References}

[1] K. Sato and H. Katayama-Yoshida, "Material design for transparent ferromagnets with $\mathrm{ZnO}$-based magnetic semiconductors," Japanese Journal of Applied Physics, vol. 39, no. 6 B, pp. L555-L558, 2000.

[2] S. Y. Lee, E. S. Shim, H. S. Kang, S. S. Pang, and J. S. Kang, "Fabrication of $\mathrm{ZnO}$ thin film diode using laser annealing," Thin Solid Films, vol. 473, no. 1, pp. 31-34, 2005.

[3] M. A. Garcia, J. M. Merino, E. F. Pinel et al., "Magnetic properties of $\mathrm{ZnO}$ nanoparticles," Nano Letters, vol. 7, no. 6, pp. 1489-1494, 2007.

[4] U. Ozgur, Y. I. Alivov, C. Liu et al., "A comprehensive review of ZnO materials and devices," Journal of Applied Physics, vol. 98, no. 4, Article ID 041301, 2005.

[5] J. K. Furdyna, "Diluted magnetic semiconductors," Journal of Applied Physics, vol. 64, no. 4, article R29, 1988.

[6] R. Ayouchi, D. Leinen, F. Martín, M. Gabas, E. Dalchiele, and J. R. Ramos-Barrado, "Preparation and characterization of transparent $\mathrm{ZnO}$ thin films obtained by spray pyrolysis," Thin Solid Films, vol. 426, no. 1-2, pp. 68-77, 2003.

[7] C. T. Chien, H. H. Yang, Y. F. Chen et al., "Polarizationdependent confocal Raman microscopy of an individual $\mathrm{ZnO}$ nanorod," Applied Physics Letters, vol. 92, no. 22, Article ID 223102, 2008.

[8] T. K. Pathak, P. Singh, A. Singh, and L. P. Purohit, "Room temperature ferromagnetism of Ni-doped $\mathrm{ZnO}$ thin films," International Journal of Basic and Applied Sciences, vol. 1, no. 2, pp. 134-138, 2012.

[9] B. D. Cullity and S. R. Stock, Elements of XRD, Pentice-Hall, New Jersey, NJ, USA, 2nd edition, 2001.

[10] N. V. Kaneva and C. D. Dushkin, "Preparation of nanocrystalline thin films of $\mathrm{ZnO}$ by sol-gel dip coating," Bulgarian Chemical Communications, vol. 43, no. 2, pp. 259-263, 2011.

[11] R. P. Wang, g. Xu, and P. Jin, "Size dependence of electronphonon coupling in $\mathrm{ZnO}$ nanowires," Physical Review, vol. 69, no. 11, Article ID 113303, 2004.

[12] G. H. Yu, L. R. Zeng, F. W. Zhu, C. L. Chai, and W. Y. Lai, "Magnetic properties and X-ray photoelectron spectroscopy study of $\mathrm{NiO} / \mathrm{NiFe}$ films prepared by magnetron sputtering," Journal of Applied Physics, vol. 90, no. 8, pp. 4039-4043, 2001.

[13] R. Chauhan, "Structure and optical properties of $\mathrm{Zn}_{1-x} \mathrm{Ni}_{x} \mathrm{O}$ nanoparicles by coreprecipitation method," Opto-Electrophoretic Detection of Bio-Molecules, vol. 17, 2011.

[14] J. I. Pankove, Optical Process in Semiconductors, Pentice-Hall, New Jersey, NJ, USA, 1971.

[15] C. Gümüş, O. M. Ozkendir, H. Kavak, and Y. Ufuktepe, "Structural and optical properties of zinc oxide thin films prepared by spray pyrolysis method," Journal of Optoelectronics and Advanced Materials, vol. 8, no. 1, pp. 299-303, 2006.

[16] E. Burstein, "Anomalous optical absorption limit in InSb," Physical Review, vol. 93, no. 3, pp. 632-633, 1954.

[17] T. S. Moss, "The Interpretation of the properties of indium antimonide," Proceedings of the Physical Society B, vol. 67, no. 10, article 775, 1954. 

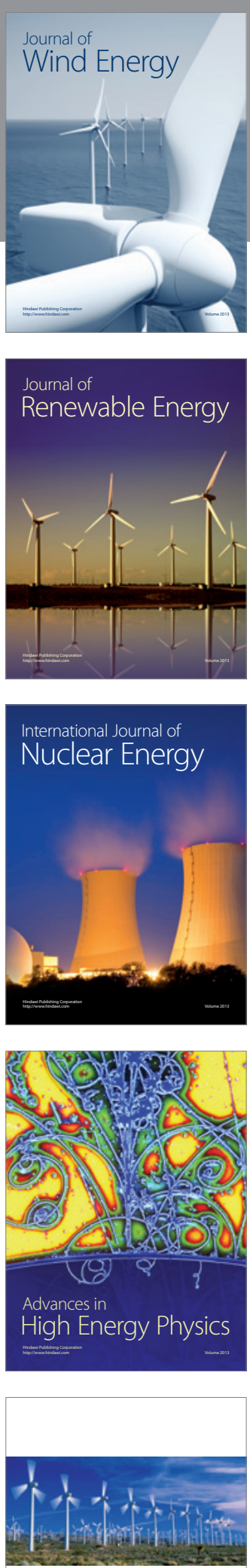

ISRN

Renewable Energy
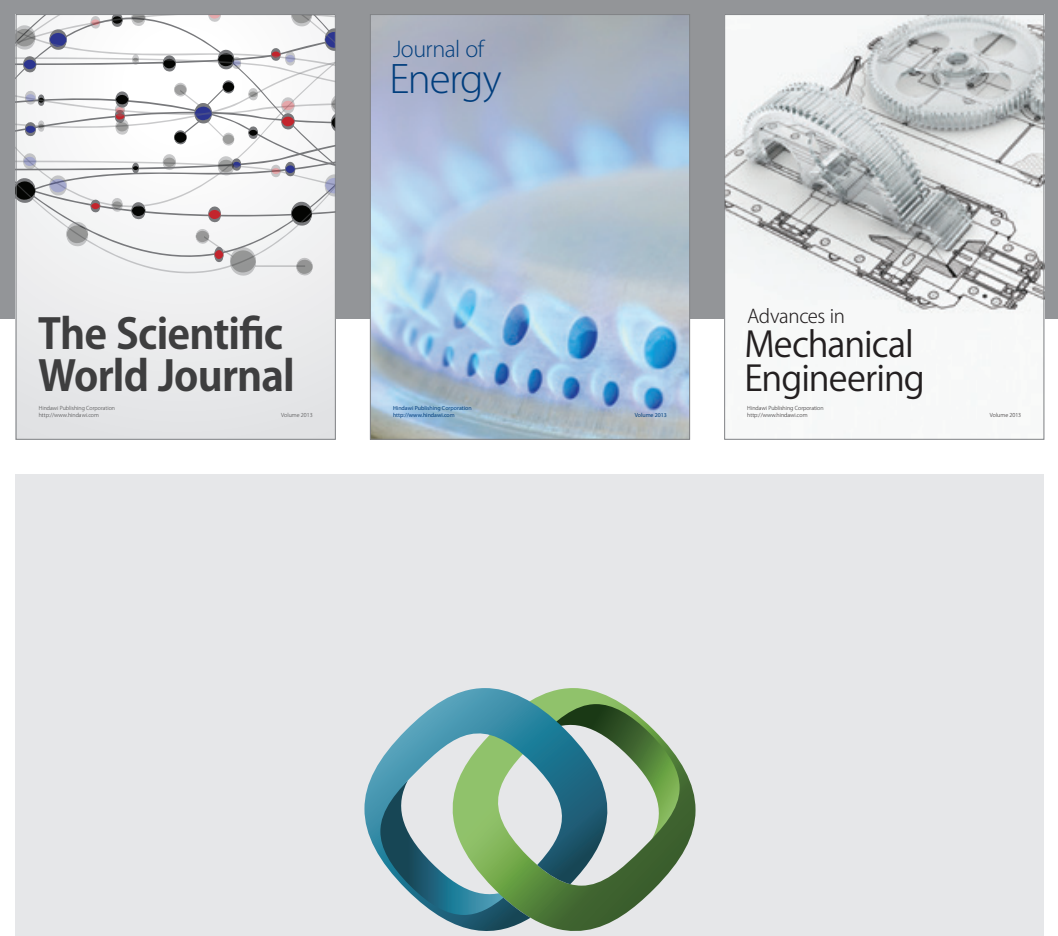

\section{Hindawi}

Submit your manuscripts at http://www.hindawi.com
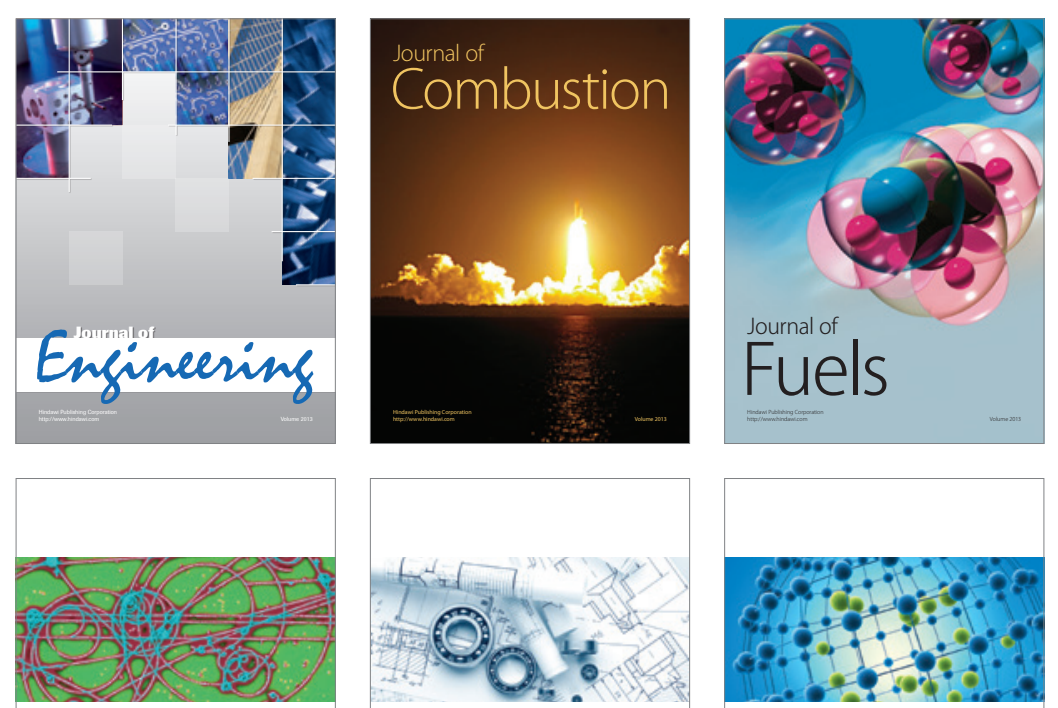

ISRN

High Energy Physics

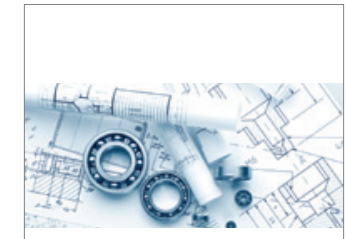

ISRN

Mechanical

Engineering

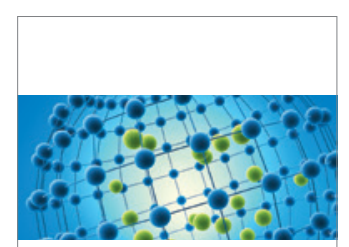

ISRN

Chemical

Engineering
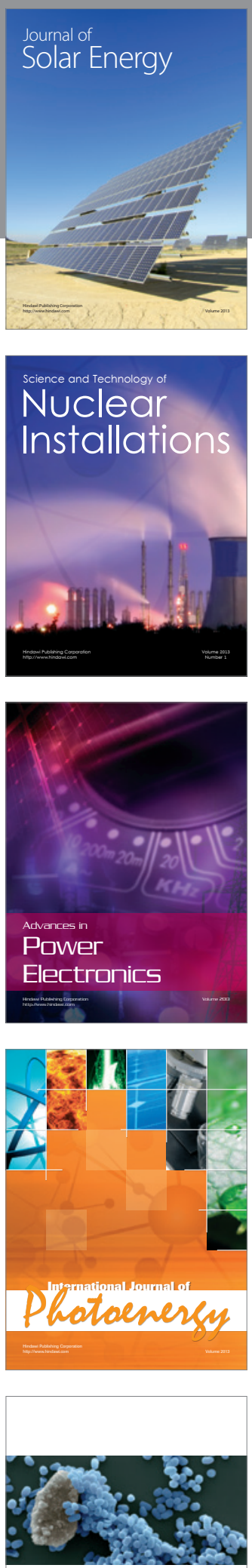

ISRN

Biotechnology 

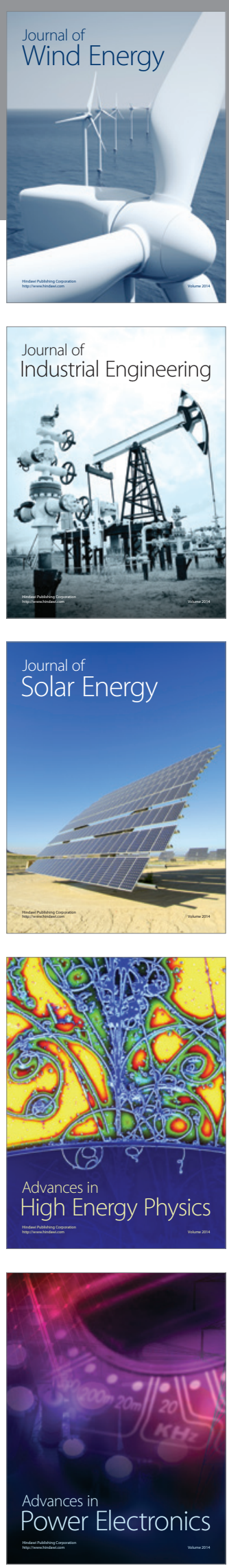
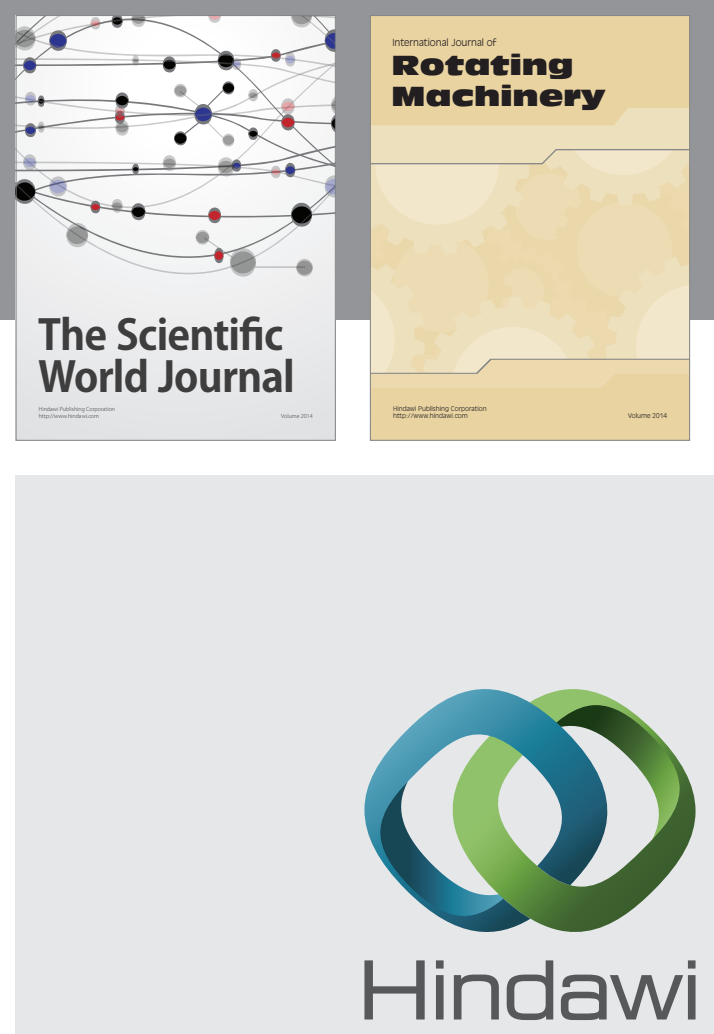

Submit your manuscripts at

http://www.hindawi.com
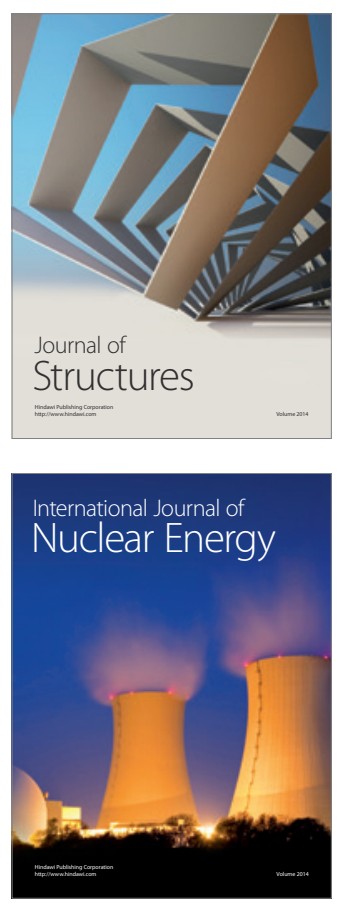
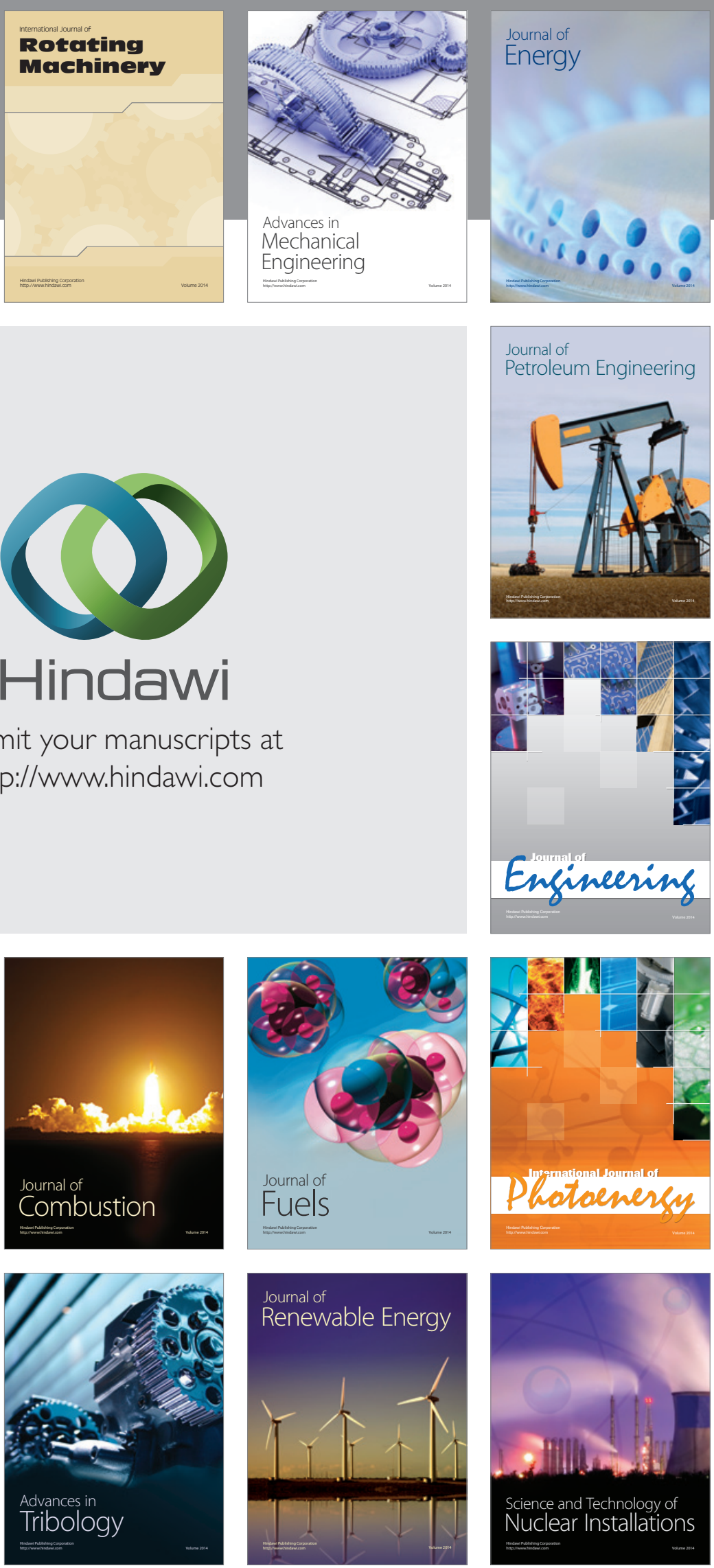